\title{
Crowdsourcing as an IT help tool to determine impact in the health sector
}

\author{
Juan Diego López ${ }^{1,}{ }^{*}$, Roberto Osorio ${ }^{2}$, Luis Moreno $^{3}$, Jorge Gomez $^{4}$, Francisco López ${ }^{5}$, Aldo Vilardy ${ }^{6}$, Jairo Gutierrez ${ }^{7}$, \\ Liliana Gomez ${ }^{8}$ and Francisco Veléz $z^{9}$ \\ ${ }^{1}$ UCEVA Asesor, Vicerrectoria de Investigaciones, Tuluá - Valle, Colombia \\ ${ }^{2}$ ECCI Asesor Vicerrectoria de Investigaciones, Bogotá, Colombia \\ ${ }^{3}$ LUMON Ceo, Dirección, Bogotá, Colombia, \\ ${ }^{4}$ UCEVA Vicerrector, Vicerrectoria de Investigaciones, Tuluá - Valle, Colombia \\ ${ }^{5}$ LV Consultores, Departamento de Informática, Tuluá - Valle, Colombia \\ ${ }^{6}$ LV Consultores, Departamento de Informática, Bogotá, Colombia \\ ${ }^{7}$ UCEVA Rector, Rector Institucional, Tuluá - Valle, Colombia \\ ${ }^{8}$ UNIMUNUTO Departamento de Informática y Electrónica, Director, Bogotá, Colombia \\ ${ }^{9}$ UCEVA Docente, Vicerrectoria de Investigaciones, Tuluá - Valle, Colombia
}

\begin{abstract}
The aim of this research was to propose a solution which applies the Crowdsourcing concept as the use of Information Technology to determine the perception of a social environment, which can perform a raised topic by an entity. In this case, the perception of Ruben Cruz Velez hospital with respect to: What opinion would you give about the Hospital Prevention and Promotion program?, in order to evaluate throughout Crowdsourcing, the Monitoring and Control Inspection (IVC) mechanisms for the provision of health services and component effectiveness, processes and standards of the Mandatory Quality Assurance System and their impact on provision of health services to users in an accessible and equitable manner.It is important to highlight that the development of a web platform that allows citizen participation to evaluate the mechanisms of Inspection of Monitoring and Control (IVC) of the provision of health services, analyzing the effectiveness of corrective actions and their impact on The provision of services to users in an accessible and equitable manner. Undoubtedly, in order to understand the current development and situation of traditional medicine in diverse geographical and cultural contexts, the way it adapts to its environment, and the type of health care available, it is necessary to locate it in the context of the models Health care in which it is inserted. The analysis of the current situation of traditional health systems, seen as subsystems of the total system, serves as a starting point for a more detailed reflection of their dynamics in Colombia, so thanks to the development of the CROWDSOURCING methodology as a tool To understand the current situation will help us to make valuable decisions for the future of the health sector particularly the beneficiary entities.
\end{abstract}

\section{Introduction}

The present research is based on work carried out in the Ruben Cruz Velez Hospital of Tuluá, Valle del CaucaColombia. Work funded by Unidad Central del ValleUCEVA.

One of this work motivation is to evaluate, throughout crowdsourcing, the provision of health service and component effectiveness, processes and standards of the mandatory system of quality assurance and its impact on the provision of these services to users in an accessible and equitable manner. And in turn, evaluate and value citizen participation, in order to identify possible gaps and shortcomings of the general health system.
Studies with the use of new technologies, in particular, all those advances related to the internet, have allowed the birth of a new multitude processes and applications, which were based on the network of networks: Web 2.0, evolution of the traditional web (1.0), after the .com bubble sites, and the applications which represent its principles and currently some of their fruits.

It is important to note that "Web 2.0" concept, was coined by O'Really ${ }^{1}$ in the year of 2005 and although it is a difficult term to define ${ }^{2}$, the truth is that it has meant a radical change in the way to use the Internet. Specifically, Web 2.0 refers both to a way of using web and technological paradigm, comprises both a set of new web technologies, a set of business strategies as well as a series of social trends ${ }^{3}$.

\footnotetext{
*Corresponding author: jdlopez@uceva.edu.co
} 
Undoubtedly, within the history and evolution of Crowdsourcing ${ }^{4}$, this was defined for the first time, by an American journalist, Jeff Howe, where in 2006 he defined it as the open call initiated by a company or institution normally performed by an employee directed to an indefinite group of individuals ("crowd"), often large in order to outsource a function, ${ }^{5}$. Therefore, Several authors have tried so far to elaborate a definition, some focusing on the use of crowdsourcing as a process of problem solving $6,{ }^{7}$, others as a way to outsource tasks $^{8}$. However, Crowdsourcing refers to a collective intelligence 9, and does not have a theoretical basis which is based in this research ${ }^{4}$, although this problem is being remedied.

Nevertheless, within the context of health care, various forms of crowdsourcing have been used for disaster response10 and a disease outbreak ${ }^{11}$. These forms of crowdsourcing relied on unpaid volunteers to provide services such as language translation or geolocation. One example is the 23andMe company, which is the largest community of personal genotype, with more than 100,000 subscribers serving the genome, and more than $75 \%$ of the community has expressed its willingness to participate in research studies organized by the company ${ }^{12}$. In addition, a large case led by the National Human Genome Research Institute, referring to associated tests like type 2 diabetes, prostate cancer, cholesterol levels, and multiple sclerosis ${ }^{12}$. It can be highlighted that according to what PatientsLikeMe and 23andMe companies perform, these are types of research studies based on crowdsourcing ${ }^{13}$.

Therefore, PatientsLikeMe \& 23andMe, are crowdsourcing operators in health and research studies, studies carried out in improvement areas of disease characterization and measurement, research aspects of drugs use, exploration of social health experience in terms of network user, disease establishment and the basis of traits with genetic associations.

One of the cases of crowdsourcing in health was developed by World Community Grid ${ }^{4}$, a non-profit project which aimed to support scientific research projects for the benefit of humanity. The project started in 2004 to accelerate the discovery of a cure for smallpox. The crowdsourcing approach, have allowed researchers to examine the effect of 35 million pharmacological compounds, and finally select 44 of particular therapeutic interest. Since then, WCG has extended its objectives to other areas, such as the human immunodeficiency virus, and two promising inhibitors, which have promoted the AIDS treatment advance. Similarly, WCG Have an active project since November 2011, the GO project Fight Against Malaria, whose objective is to discover pharmacological compounds, which are effective against the more resistant forms of malaria ${ }^{15}$.

Nevertheless, scientists of The Scripps Research Institute, La Jolla-California, USA, used IBM network in the World Community to computationally evaluate millions of candidate compounds against different molecular pharmacological systems of the malaria parasite. Another project is the GO16, where Malaria is just one example of the potential that crowdsourcing offers us, as a proven methodology in other fields, addressed to find solutions to this and other diseases.

\section{Material and methods}

The present case is addressed to propose a solution, which applies the Crowdsourcing concept for weighting of surveys and determination of the perception, which have allowed a social environment in front of a subject that an entity raises.

In this case, several alternatives are evaluated and the feeling evaluation is selected throughout an application of regular expressions to the opinion expressed by a community, as well as a weighting of the responses selected to one or more questions that an entity raise.

To obtain the above, the themes are defined as follows:

a) Implement a security system and database profiles.

b) Implement an option for handling regular expressions.

c) Implement an administration for creation of survey topics, creation of questions, opinion topics and association of regular expressions.

d) Implement a survey processing and opinion processing system with bar graph presentation with the obtained result.

e) Implement options to allow the people registration in a community who want to participate in the process throughout surveys and opinion.

f) Implement options to allow surveys to be answered and provide input from the registered community.

Starting from what is stated in the description, the following architecture for the solution is presented as shown in Figure 1.

Fig. 1. Architecture 


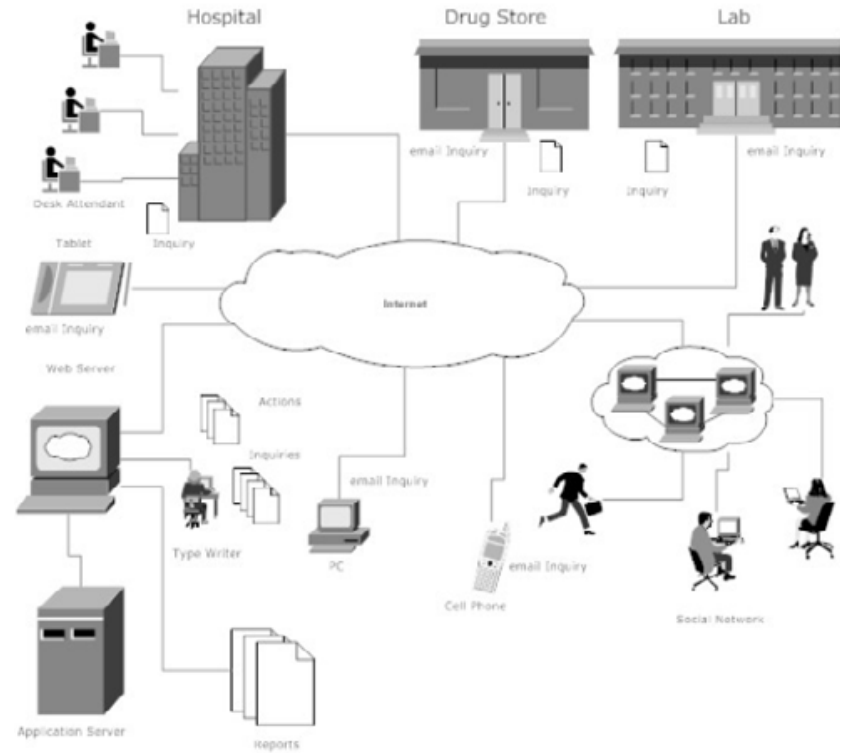

The architecture is based on a JEE Enterprise Java Web Design, using the following components: Front-End: Framework JSF adding to framework PrimeFaces 5.0. Back-End: Framework JSF with EJB 3.0 (JEE). Respectively, allows access to Relational Database: Framework JPA, specifically the EclipseLink component.

The project structure, as shown in Figure 2, is a general structure for developing the solution, creating and locating sources in its packages.

Fig. 2. Project structure

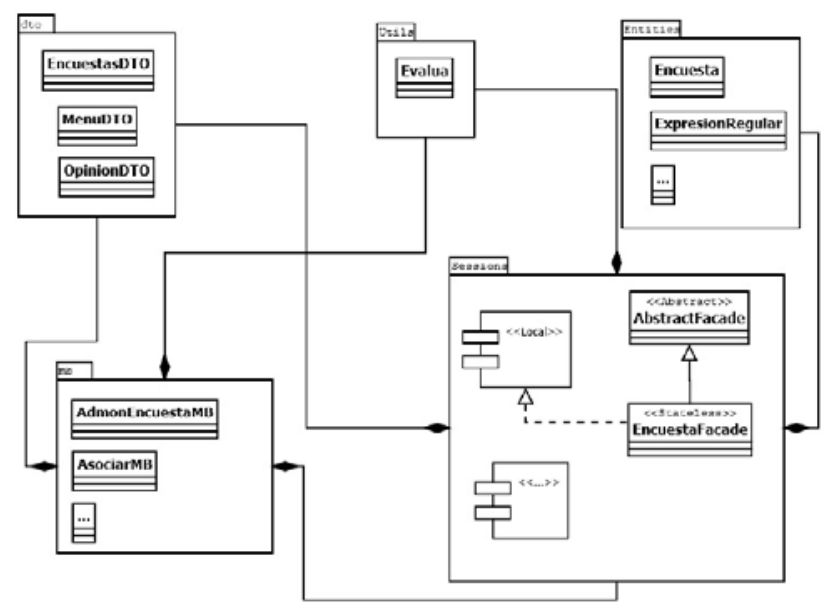

For development a project is created Web JSP using IDE Netbeans 8.0.2 full version. To open the project, simply select the option to open projects from the IDE.

Within the requirements for installation is needed as Software:

-Java development kit version 7 update 80 . http://www.oracle.com/technetwork/es/java/javase/down loads/jdk7-downloads-1880260.html -Mysq15.5

https://dev.mysql.com/downloads/windows/installer/5.5. html -Glassfish4.1

https://glassfish.java.net/download-archive.html

\section{Results}

The project considered for the case study, a question to be developed using the crowdsourcing methodology, at the Ruben Cruz Velez Hospital in Tuluá - Valle del Cauca - Colombia, which were performed to get the following results.

Fig. 3. Option "Theme"

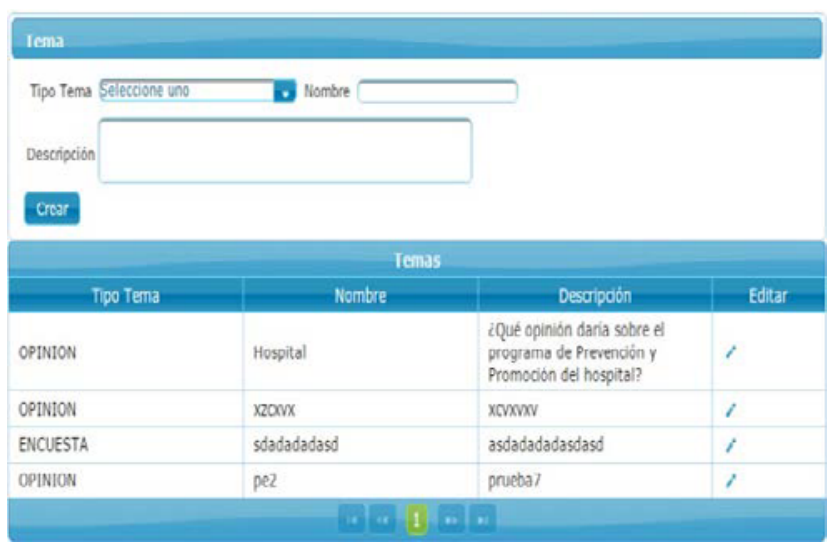

To create a theme, you must select one of the options of type, which are Survey or Opinion type. In addition, gives a name to the subject, which is typed in the text box called name. To facilitate a more precise objective, it describes what is wanted with the subject and finally it is pressed the button create with which, a subject is stored in database. The description should be as telling as possible so that those who are going to conduct the survey or say understand what you want with your answers or comments.

Once created the theme, is displayed in the grid which allows a future modification.

If you want to change, press the pencil icon in the grid next to the profile name, after which you can modify the profile. To be stored after modifying, the $\checkmark$ icon is 
pressed. Otherwise, if you want to cancel, press the $\mathrm{X}$ icon. Note that every time you create a theme of a specific type, the previous theme will be closed and the new theme, will be active.

Given these concerns, Crowdsourcing is used as a methodology for health, where an opinion question is performed throughout web and social networks in such a way the Ruben Cruz Hospital users in Tuluá, Valle Colombia. A particular theme of the hospital, for this case was asked:

What opinion would you give about the Hospital Prevention and Promotion Program?, in order to evaluate, throughout Crowdsourcing, the Surveillance and Control Inspection (SCI) mechanisms for provision of health services and the component effectiveness, processes and standards of the Mandatory Quality Assurance System and its impact on the provision of health services to users in an accessible and equitable manner.

Fig.4. Crowdsourcing for health

Opine on the subject

What opinion would you give about the Hospital Prevention and Promotion Program?

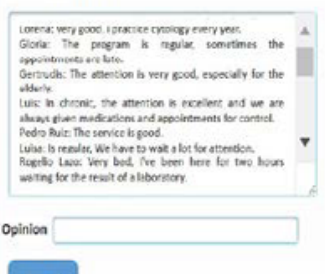

Send

In this process, each user gave his opinion as shown in Figure 4. From there, each of them made their opinion reaching about 400 users who opined and it was given as a general result, users are not at ease with the Service, as shown in Figure 5. Given this concerns, a report was presented to the hospital management to take the corresponding corrective, and will continue to use the tool for decision-making senior management.

Fig.4. Result

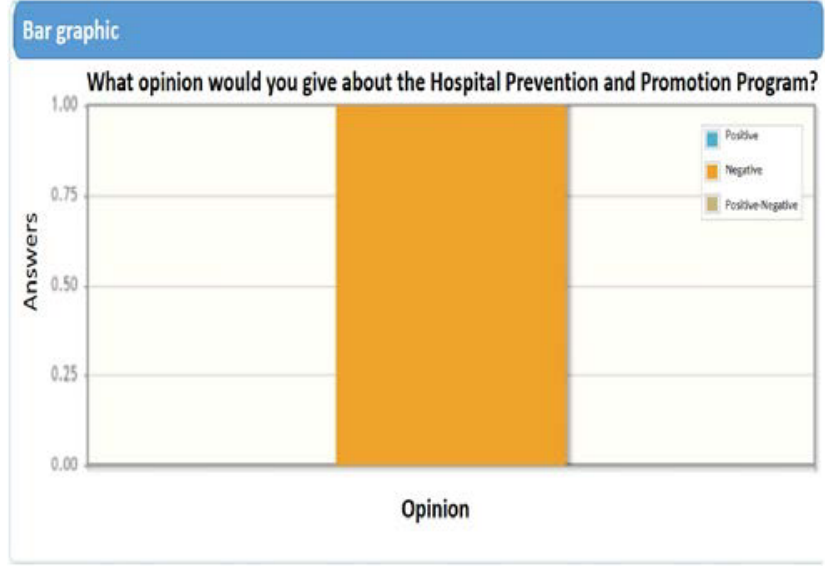

\section{Considerations}

Crowdsourcing facilitates the implementation of innovation models and development of actions, which support improvements and the achievement of benefits in innovation processes, this provides more accurate and reliable estimates for a company or organization to base some of their decisions or actions on knowledge and work group of external groups.

Undoubtedly, to understand the current development and situation of traditional medicine in diverse geographic and cultural contexts, the way in which it adapts to its environment, and the type of health care available, it is necessary to locate it in the models context of health care in which is inserted.

It is important to note that the current situation analysis of traditional health systems, seen as subsystems of the total system, serves as a starting point for a more detailed reflection of its dynamics in Colombia. In this way, throughout the development of Crowdsourcing methodology, have allowed to understand the current situation and provides more accurate and reliable estimates of valuable decisions for the future of the health sector, particularly the two beneficiary entities.

It is noteworthy that the implementation and validation of a technological strategy to address and solve problems for the general social security system in health programs in health promotion and disease prevention in high rural and territorial environments Dispersed territories. Case study center of the cauca valle.

\section{Final considerations}

We describe the results of Crowdsourcing implementation in the health case study at Ruben Cruz Velez Hospital in the city of Tuluá, Valle - Colombia. Given these concerns, this paper is derived from the project "Control system, inspection, health services surveillance in Colombia for the general system of social security in health throughout ICT services and processes 
management", a project funded by ICT (Information and Communication Technologies) Ministry and Colciencias in Colombia.

\section{Acknowledgements}

Mainly to UCEVA- Unidad Central del Valle Del Cauca and their valuable contribution for research realization as a pioneering project in Latin American, and also an acknowledgement to Dr. Julio Cesar Toro, for opening the doors of the Ruben Cruz Velez Hospital as beneficiary.

\section{References}

1. O'Reilly, T. (2007) what is Web 2.0: Design Patterns and Business Models for the Next Generation of Software. Communications \& Strategies, 1, 17

2. Cormode, G. and Krishnamurthy, B. (2008) Key differences between Web 1.0 and Web 2.0. First Monday, 13 (6).

3. Murugesan, S. (2007) Understanding Web 2.0. IT Professional, 9(4), 34-41

4. Lopez Juan D. González F. Estelles E. Prieto F. Crowdsourcing: Para la Prevención y Promoción de la Salud en Colombia. www.laccei.org/LACCEI2013Cancun/Referee Papers/RP056.pdf Eleventh LACCEI Latin American and Caribbean Conference for Engineering and Technology (LACCEI'2013)

5. Howe, J. (2006) Crowdsourcing: A definition. http://crowdsourcing.typepad.com/cs/2006/06/crowd sourcing_a.html (Last access, april, 2016).

6. Brabham, D. C. (2008). Crowdsourcing as a model for problem solving. Convergence: The International Journal of Research into New Media Technologies, 14(1), 75

7. Vukovic, M. and Bartolini, C. (2010) Towards a Research Agenda for Enterprise crowdsourcing. In: M. Tiziana and S. Bernhard (eds) Leveraging Applications of Formal Methods, Verification, and Validation (Springer, Berlin/Heidelberg, 2010) 425434 [Lecture Notes in Computer Science 6415].

8. Oliveira, F., Ramos, I., Santos, L. (2010) Definition of a crowdsourcing Innovation Service for the European SMEs. In: Daniel F. et al. (eds.) Current Trends in Web Engineering (Springer, Berlin/Heidelberg, 2010), pp. 412-416.

9. Schenk, E. and Guittard, C. (2011) towards a characterization of crowdsourcing practices. Journal of innovation economics, 1(7), 93-107.
10. Denyer, D., Tranfield, D. and Van Aken, J.E. (2008) Developing design propositions through research synthesis. Organization Studies, 29(3), 393-413.

11. Gao \& Barbier, 2011) Harnessing the Crowdsourcing Power of Social Media for Disaster Relief. Ieee InTeLLIGenT SySTemS Published by the IEEE Computer Society Cyber-physical-social systems ISSN 1541-1672, 2011 IEEE.

12. Freifeld, C. C., Chunara, R., Mekaru, S. R., Chan, E. H., Kass-Hout, T., Ayala Iacucci, A., \& Brownstein, J. S. (2010). Participatory Epidemiology: Use of Mobile Phones for Community-Based Health Reporting. PLoS Medicine, 7(12).

13. J.Y. Tung, N. Eriksson, A.K. Kiefer, J.M. Macpherson, B.T. Naughton, A.B. Chowdry, C.B. Do, D.A. Hinds, A. Wojcicki, J.L. Mountain Characteristics of an Online Consumer Genetic Research Cohort. 23andMe, Inc, Mountain View, CA

http://blog.23andme.com/wpcontent/uploads/2011/1 0/ASHG2011poster-JYT.pdf (Last access, March, 2016).

14. Swan, M. (2012). Crowdsourced Health Research Studies: An Important Emerging Complement to Clinical Trials in the Public Health Research Ecosystem. Journal of Medical Internet Research, 14(2). ISSN:1439-4456

15. WCG 2004." Proyecto GO Viruela", worldcommunitygrid.

http://www.worldcommunitygrid.org/research/gfam/ overview.do (Last access, March, 2016).

16. WCG 2011." Proyecto GO Fight against Malaria", worldcommunitygrid.

http://www.worldcommunitygrid.org/research/gfam/ overview.do. (Last access, March, 2016). 